\title{
Mitigating Electricity a Price Spike under Pre-Cooling Method
}

\author{
Marwan Marwan ${ }^{1}$, Pirman $^{2}$ \\ ${ }^{1}$ Electrical Engineering Department ${ }^{2)}$ Chemical Engineering Department \\ Polytechnic State of Ujung Pandang Makassar Indonesia
}

\begin{tabular}{l}
\hline \hline Article Info \\
\hline Article history: \\
Received Dec 24, 2015 \\
Revised Feb 26, 2016 \\
Accepted Mar 10, 2016
\end{tabular}

Keyword:

Cooling

Economics

Electrical Power

Modelling

Network

\begin{abstract}
The growing demand for air-conditioning is one of the largest contributors to Australia overall electricity consumption. This has started to create peak load supply problems for some electricity utilities particularly in Queensland. This research aimed to develop a consumer demand side response model to assist electricity consumers to mitigate peak demand on the electrical network. The proposed model allows consumers to independently and proactively manage air conditioning peak electricity demand. The main contribution of this research is how to show consumers can mitigate peak demands by optimizing energy costs for air conditioning in a several cases such as no spike and spike considering to the probability spike cases may only occur in the middle of the day for half hour spikes. This model also investigates how air conditioning applied a pre-cooling method when there is a substantial risk of a price spike. The results indicate the potential of the scheme to achieve energy savings and reducing electricity bills (costs) to the consumer. The model was tested with the Queensland electricity market data from Australian Energy Market Operator and Brisbane temperature data from Bureau statistic during hot days.
\end{abstract}

Copyright (C) 2016 Institute of Advanced Engineering and Science. All rights reserved.

\section{Corresponding Author:}

Marwan Marwan,

Polytechnic State of Ujung Pandang,

Perintis Kemerdekaan Street, Makassar, South Sulawesi, Indonesia.

Email: marwan_energy@yahoo.com; marwan@poliupg.ac.id

\section{INTRODUCTION}

The Smart Grid is a promising concept to cope with increasing energy demand and environmental concerns. As the main feature and construction goal of the smart grid, intelligent interaction includes twoway interaction of information and energy, to encourage electricity consumers to change the traditional usage styles and participate in the network operation actively (such as adjustment of energy consumption patterns according to real-time price), and to achieve the plug-and-play Grid-connection of the distributed generation. Thus, demand side management (DSM) technology is one of the most important parts of the smart grid. Based on the traditional functions, the smart grid DSM has new contents, including automation demand response, smart consume sequence, remote energy efficiency monitor \& control, energy efficient power generation, and so on [1]. Demand side response (DSR) ia a parth of the smart grid system can be defined as the changes in electric usage by end-use customers from their normal consumption patterns in response to changes in the price of electricity over time [2].

To implement DSR model, consumer is required to enrol as a member of a group controlled by an aggregator. To be exposed to electricity market price and network overload costs, small-consumers need an aggregator to communicate and negotiate the electricity market price and network overload. Any change in the electricity usage for the small-consumer is based on the information from the aggregator. As a result, aggregators keep and maintain communication between market operator and consumers.

In the competitive electricity market structure, the aggregator concept describes an independent agent providing its small-consumers with a wide range of innovative services including bill management, 
home management, home electricity generation, and other services [3, 4]. Based on these service provisions, the aggregator combines its consumers into a single purchasing unit to negotiate the purchase of electricity from the retailer [3]. The aggregator also negotiates demand response and behalf of the consumer with the retailer, distribution and transmission company. Many economists believe that the participation of aggregator with innovative services and consumer aggregations can offer potential solutions for small-scale consumers to effectively manage their consumption, and thereby becoming active participants in the electricity market [3-6]. The aggregation methods, the combining multiple electricity load, provides the benefits of retail electric competition for the consumer with lower electric usage called a small consumer.

In this paper, the Queensland electricity market price is chosen for the case studies. Collective benefits are typically the primary consideration for the small consumer and aggregator so these prices are used to demonstrate the minimisation procedure. The wholesale electricity market prices are published on the Australian Energy Market Operator (AEMO) website. Detailed information about AEMO price data can be found in [7].

Seasonal climate variation has a significant impact on the operation of electrical power systems. Due to the temperature rises in summer, the electricity demand will increase with the load of air conditioning or other appliances. Moreover, if the consumers all turn on the air conditioning at the same time, then the total demand will be increased. Temperature is an important driver for electricity consumption. More than $40 \%$ of end-use energy consumption is related to the heating and cooling needs in the residential and commercial sectors [8]. A load survey study undertaken by the Queensland Government indicated that each kilowatt of air-conditioning installed in Queensland costs up to \$3000 in new energy infrastructure to meet peak demand [9]. Therefore, air-conditioning usage contributes greatly to peak load growth in both the commercial and residential sectors in Queensland [10].

A price spike can be generally defined as an abnormal price value, which is significantly different from its expected value $[11,12]$. The price spike in the electricity market is an abnormal market clearing price at a time point $t$ and is significantly different from the average price. In a spike, the price could rise 100 or 1000 times higher than the normal price, which brings a high risk for the market participants [13]. This impact is not just on the consumer but also on the electricity retailer.

\section{RESEARCH METHOD}

\subsection{Numerical Optimisation}

Numerical modelling is a feasible solution to allow for unpredictable market price changes due to the interruption of major generation or other supply-side constraints. To conduct this investigation, mathematical models for the consumer participant were developed to quantify the economic effect of demand-side variation. A linear programming-based algorithm was developed to determine the optimal solution to achieve the best outcomes. In addition, the developed model was designed to be applicable for load demand constraints to give good economic performance for electricity generation, transmission and distribution.

The model shows how air-conditioning should decrease temperature loads in high temperature periods when there is a substantial risk of a price spike, that is, by applying a pre-cooling method to avoid high prices in a critical peak period. Consumers are able to operate the air-conditioning usage by controlling the desired levels of room temperature, turning on the air-conditioning when the temperature rises to a maximum threshold (i.e., $25^{\circ} \mathrm{C}$ ) then turning it off for the next period until the temperature drops to the minimum threshold (i.e., $19^{\circ} \mathrm{C}$ ). In addition, this research investigated how consumers can optimise energy costs when they have not committed to the permitted temperature. On this optimisation process, when the room temperature is less or more than the minimum or maximum temperature threshold then a penalty to the optimization process will be identified. The cycling time of the air-conditioning is based on the result of temperature optimisation.

In this research, a pre-cooling method was examined as a way to minimise energy costs. Pre-cooling is a method to reduce the room temperature in advance of a possible spike. This method is considered to be effective because it can minimise energy costs and can keep room temperatures comfortable for the consumer. However, pre-cooling is only undertaken when there is a substantial risk of a price spike because it costs a lot and the spike may not always occur on the system. However, while applying this method is expensive, it is more efficient than switching on the air-conditioning at all times during the critical time.

The objective is to minimise energy costs by optimising room temperatures. The energy cost is based on the air-conditioning status, that is, no cost when the air-conditioning status is off $\left(U_{t}=0\right)$ and market cost if the air-conditioning status is on $\left(U_{t}=1\right)$. To achieve this objective, an optimisation package such as MATLAB allows the user to carry out optimisation within operational constraints such as a permitted 
temperature range. In the optimisation process, the MATLAB optimisation toolbox function fmincon and the ordinary differential equation solver ODE45 were used.

In order to formulate the participation of the consumer in the DSR program, the energy cost model which represents the changing temperature and electricity price was developed as reported here. The optimisation problem can then be represented as minimised energy cost (Z), or mathematically[4, 5]:

$$
Z(t)=\int_{t=1}^{t=n}[(S(t) \cdot P(t) \cdot D(t) \cdot U(t)) d t]
$$

Subject to constraints $[14,15]$ :

$$
\frac{\mathrm{dT}}{\mathrm{dt}}=\frac{\mathrm{Q} \cdot \mathrm{A} \cdot\left(\mathrm{T}_{\mathrm{o}}(\mathrm{t})-\mathrm{T}(\mathrm{t})\right)}{\mathrm{H}}-\frac{B \cdot \mathrm{U}(\mathrm{t})}{\mathrm{H}}
$$

where:

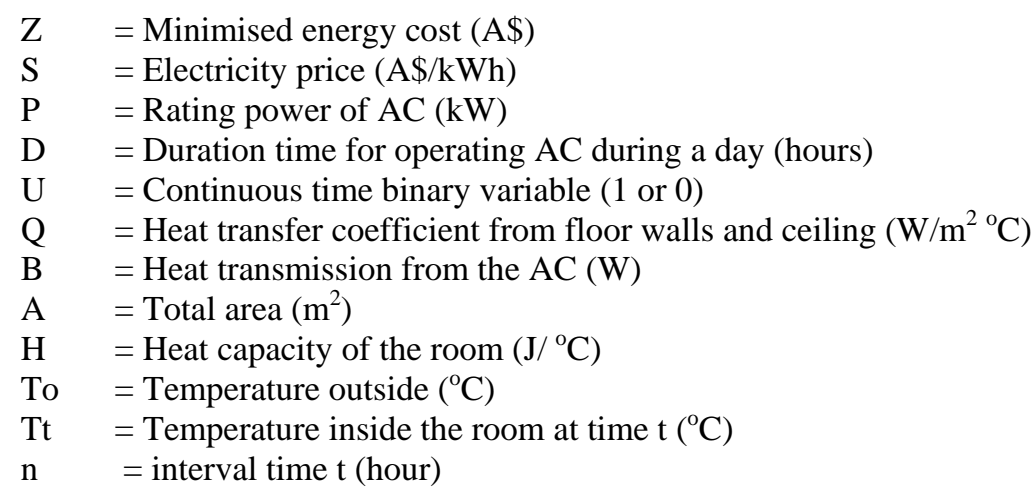

During the optimization, if the room temperature is more or less than the maximum or minimum temperature (Tmax or Tmin) threshold, the minimization will add a penalty to the computed cost.

If $\mathrm{T}(\mathrm{t})>\operatorname{Tmax}$ or If $\mathrm{T}(\mathrm{t})<\mathrm{Tmin}$ Then Penalty $=\mathrm{K}$

Else Penalty $=0$

Therefore, the energy cost will be calculated by:

$$
Z(t)=\int_{t=1}^{t=n}[(S(t) \cdot P(t) \cdot D(t) \cdot U(t)) d t]+K
$$

\subsection{Data Processing}

\subsubsection{Price Spike in the Electricity Market}

In the present research, after analysis of the historical data, a threshold value of A\$75 per MWh was used for analysis of the Queensland electricity market during weekday periods. This means any regional reference price more than A\$75 per MWh is called a price spike. The average of the electricity prices under A \$75 per MWh is called the non-spike price, which in this period was A\$30.69 per MWh. Figure 1 indicates the RRP of the electricity market in Queensland during hot days in 2011-2012 [7]. The data presented in the table shows clearly that any price above the red line is a so-called price spike.

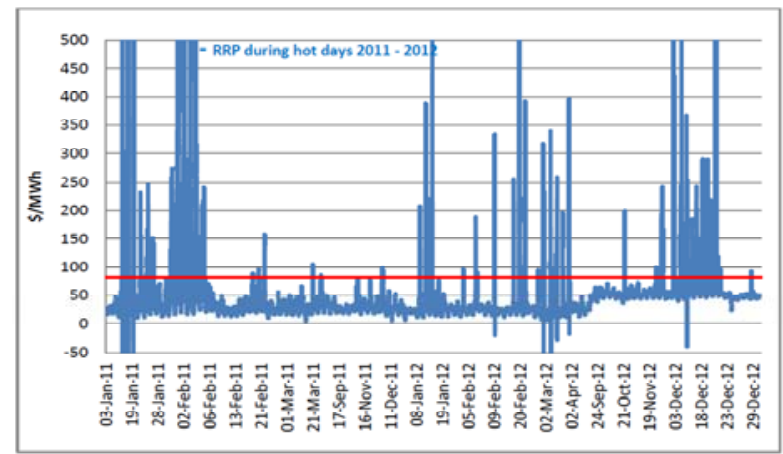

Figure 1. Electricity market price in Queensland during hot days in 2011-2012 [7] 


\subsubsection{Hot Days and Outside Temperature}

In this research, any day on which the average daily temperature was more than $30^{\circ} \mathrm{C}$ is called a hot day, as given in Figure 2. Figure 3 summarises an example of classic fluctuations in outside temperatures in Brisbane on 29 February 2012. The temperature is typically at its lowest level during the morning and at night time. Normally, the daily outside temperature increases in the middle of the day. In the example, the highest temperature occurred from around 12:00 to 17:00. The outside temperature around these times was more than $30^{\circ} \mathrm{C}$. The maximum temperature of $35^{\circ} \mathrm{C}$ occurred at $15: 00$. The minimum temperature of $18^{\circ} \mathrm{C}$ occurred in the early morning (05:00 to $05: 45)$. The average temperature was $25^{\circ} \mathrm{C}$.

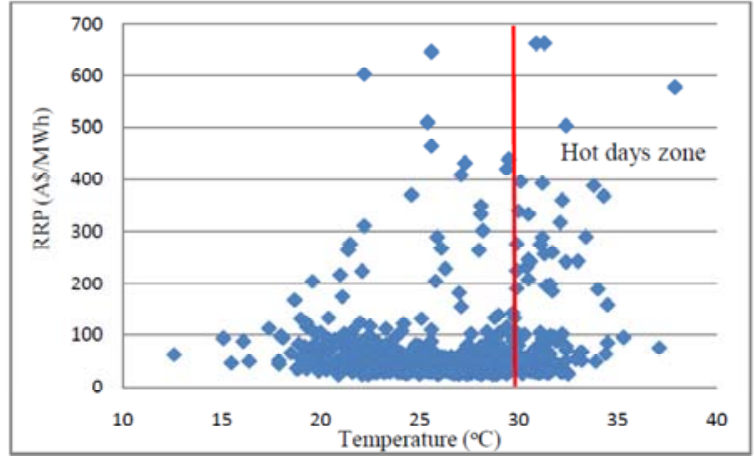

Figure 2. Classification of hot days, 2011 to 2012

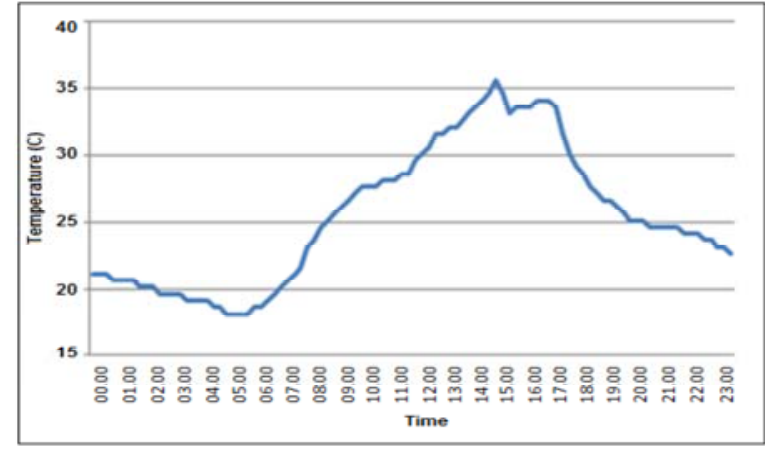

Figure 3. Brisbane outside temperature (To) on 29 February 2012

\section{RESULTS AND ANALYSIS}

There are various ways to implement the DSR in the use of air-conditioning. The Markov birth and death process has been developed to manage small package air-conditioner loads based on a queuing system. This model enables residents with small air-conditioner loads to participate in various load management programs whereby they can receive incentives and lower their electricity bills while their conveniences are taken into account [16]. This model provides effective and convenient load management measures to both the power company and the consumer. Incentives and compensation are recognised by the utility company based on the level of participation of the consumers [16]. In this model, the electricity price was not based on the electricity market price. Therefore, the aggregator was not required to control small consumers. On the other hand, these models are not appropriate for anticipating a price spike and seasonal climate changes in Australia. As a result, these models were not considered as a pre-cooling method to avoid high costs.

A simple control strategy is also used to manage the air-conditioning in a DSR program in Kuwait. Due to the normal operation of air-conditioning in Kuwait on a 24 hour basis, the control system provides comfortable conditions during the occupancy period only. For example, the system is applied for five periods during a day: (i) 03:30-04:00, (ii) 12:00-13:00, (iii) 15:15-16:00, (iv) 18:00-18:30, and (v) 20:00-21:00. To achieve acceptable comfort conditions during these periods, a pre-cooling method is applied [17]. The precooling method is applied by extending the operation time of the air-conditioning. The pre-cooling method is not based on the substantial risk of the price spike. Therefore, this method is not effective to be applied on the system if a price spike happens.

The process of consumer to minimize energy will while keeping comfort within specification is to control each switching instant of the AC. When the total cost is minimized then in many cases where price risk is low it is appropriate to make no special preparation. However when the price risk is high the optimal switching pattern makes use of pre-cooling. At the level of optimization with constraints no other outcome is feasible. Other methods of cost reduction are examined above but none of these had the potential for the same level of savings found in this research.

Consumers should start to apply the DSR program to optimise the air conditioning as soon as they receive information from the aggregator. Due to the pattern of high outside temperature, the consumer is required to participate in the DSR program starting from 10:00 to 19:00. The energy cost was calculated when the air conditioning was on, and the cost was zero when the air conditioning was off. This method continued until the time of operating the air conditioning had expired. To make the temperature comfortable for the consumer, the room temperature was only allowed to be between $19^{\circ} \mathrm{C}$ and $25^{\circ} \mathrm{C}$. This means the temperature was not allowed to reach the maximum and minimum permitted temperatures. For the purpose of 
the simulation, the starting point temperature of $22^{\circ} \mathrm{C}$ was chosen with the air conditioning status off. Table 1 summarises the parameters of the typical room and the air conditioning used in this optimisation.

Table 1. Parameter of the Example Room Used in this Analysis

\begin{tabular}{llcc}
\hline No & \multicolumn{1}{c}{ Parameters } & Unit & Value \\
\hline 1 & Heat transfer coefficient from floor wall and ceiling (Q) & 1 & $\mathrm{~W} / \mathrm{m}^{2}{ }^{\circ} \mathrm{C}$ \\
2 & Total area (A) & 54 & $\mathrm{~m}^{2}$ \\
3 & Heat capacity of the room (H) & 48 & $\mathrm{~J} /{ }^{\circ} \mathrm{C}$ \\
4 & Heat transfer from the air conditioning (B) & 900 & $\mathrm{~W}$ \\
5 & Reference of temperature & 22 & ${ }^{\circ} \mathrm{C}$ \\
6 & Hysteresis & 3 & ${ }^{\circ} \mathrm{C}$ \\
7 & Maximum temperature & 25 & ${ }^{\circ} \mathrm{C}$ \\
8 & Minimum temperature & 19 & ${ }^{\circ} \mathrm{C}$ \\
9 & Rating power of air conditioning (P) & 2.6 & $\mathrm{~kW}$ \\
10 & Number of switch change events & 20 & \\
\hline
\end{tabular}

\subsection{Cost as a Function of a Price Spike Without DSR Program}

The aim of the controller is to maintain the temperature of the room between some lower and upper temperatures in order to keep it within comfortable limits. For this simulation, the starting point of $22^{\circ} \mathrm{C}$ was chosen with the air conditioning status off. The lower and upper temperatures were $22^{\circ} \mathrm{C}$ to $24^{\circ} \mathrm{C}$. The air conditioning was turned on once the temperature rose to the selected maximum. Next, the air conditioning was turned off once the temperature dropped to the selected minimum. With the air conditioning off, the temperature could increase and rise to the selected maximum. The typical operation of the air conditioning is continuous without control by the DSR program. To operate the air conditioning in this case, the consumer did not consider a price spike. Figure 5 illustrates the cycling temperature and the market cost if a spike may occur in the middle of the day.

In this simulation, there are 20 switch edges to compute the energy cost for the air conditioning. If $\mathrm{S}_{\mathrm{S}}$ is the electricity price when a spike occurs, $\mathrm{K}$ is the penalty, then the total market cost for the spike case $\left(\mathrm{MC}_{1}\right)$ is determined by the following equation:

$$
\mathrm{MC}_{1,2,3}(\mathrm{t})=\int_{\mathrm{t}=1}^{\mathrm{t}=\mathrm{n}}\left[\left(\mathrm{S}_{\mathrm{s}}(\mathrm{t}) \cdot \mathrm{P}(\mathrm{t}) \cdot \mathrm{D}(\mathrm{t}) \cdot \mathrm{U}(\mathrm{t})\right) \mathrm{dt}\right]+\mathrm{K}
$$

Equations (1) to (6) were used to compute the results of simulation without DSR program when a half hour spike may occur in the middle of the day, as shown in Figure 4.
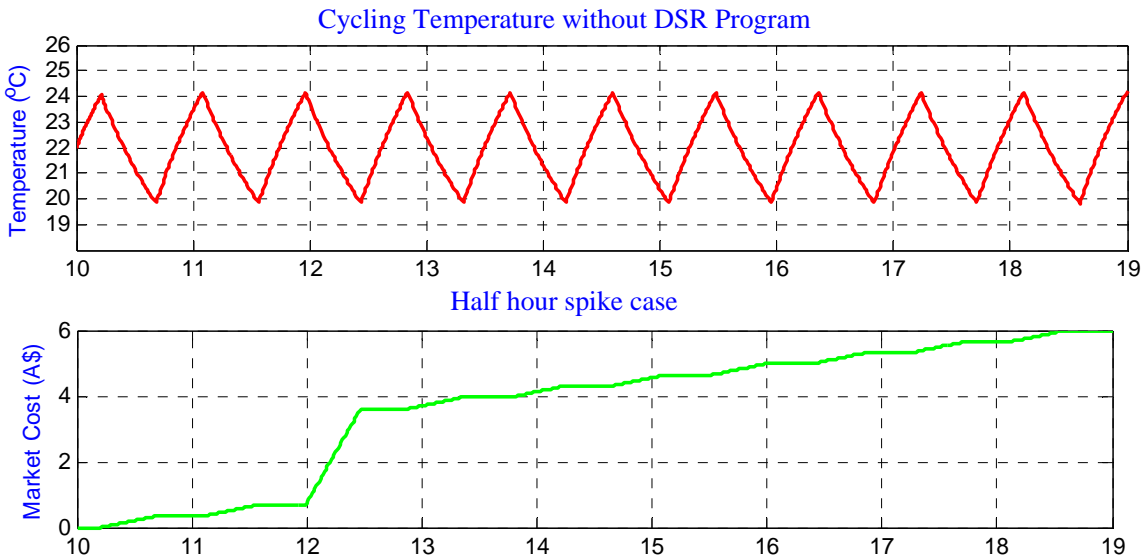

Figure 4. Cycling temperature and market cost without DSR

As shown in Figure 4, the calculation of the electricity cost during this period was based on the air conditioning status. The electricity cost increased when the temperature was being reduced by having the air conditioning on. However, there was no electricity cost when the air conditioning was off or electricity costs 
were not calculated when the air conditioning was off. The electricity cost calculation started from switch number 1 to number 2 . Then, the air-conditioning was turned off again between switch numbers 2 to 3 , when the electricity cost is zero. The type of operation was continuous for all switching and all times. The consumer/aggregator pays the cost according to the normal price before and after a spike happens. The price spike was only calculated when the spike happened in the middle of the day. In this case, thre kinds of spike were considered, only for the half hour spike. If a half hour spike $\left(\mathrm{MC}_{1}\right)$ is defined for the total market cost without the DSR program, then the total market costs of every spike are as presented in Table 2.

Table 2. Total Market Cost Without DSR Program

\begin{tabular}{cc}
\hline & Half Hour Spike $\left(\mathrm{MC}_{1}\right)$ \\
\hline Total Market Cost (A\$) & 5.99 \\
\hline
\end{tabular}

\subsection{Cost as a Function of a Price Spike Under DSR Program Considering to the Probability Spike}

The control system optimised the room temperature of the air conditioning to define the energy cost for consumers. The aim of the controller is to maintain the temperature between the permitted maximum and minimum temperatures in order to provide a comfortable room temperature for the consumer. In this optimisation, the maximum and minimum temperatures were $25^{\circ} \mathrm{C}$ and $21^{\circ} \mathrm{C}$. Temperature starting of $22^{\circ} \mathrm{C}$ was chosen. Under DSR program the cycling temperature room was longer than without DSR program. This is to give more option and more flexibility for the optimisation. In addition, since the price spike may occur in the middle of the day, the consumer is required to optimise to achieve minimum expected energy costs.

Under the DSR program, the control system applied the pre-cooling method to avoid high costs when a spike happens. Similar to the previously described method, the air conditioning was turned on once the temperature rose to the maximum permitted temperature. Then, it was turned off when the temperature dropped to the minimum permitted temperature. The control system kept the room temperature between the maximum and minimum permitted temperatures. If $\mathrm{S}_{\mathrm{s}}$ is the electricity price when a spike occurs, $\mathrm{K}$ is the penalty, then the total market cost for the spike case $\left(\mathrm{MC}_{\mathrm{s}}\right)$ is determined by the following equation:

$$
\mathrm{MC}_{\mathrm{s}}(\mathrm{t})=\int_{\mathrm{t}=1}^{\mathrm{t}=\mathrm{n}}\left[\left(\mathrm{S}_{\mathrm{s}}(\mathrm{t}) \cdot \mathrm{P}(\mathrm{t}) \cdot \mathrm{D}(\mathrm{t}) \cdot \mathrm{U}(\mathrm{t})\right) \mathrm{dt}\right]+\mathrm{K}
$$

To consider the case where there is a finite probability that a price spike may occur at the middle of the day, then we needed a new form of optimisation. Here we did not know what the price would be, so we forced the switching to be the same up until the spike time. The switching would be different from that time onwards, depending on whether the spike really occurred. In this case, there were four switches which characterised the time up to the price event and a remaining 16 switches under the two switching scenarios. This gave a total of 36 switch edges to optimise. In this research, the probability of a half hour spike was $2.2 \%$. To consider when there is a finite probability $\left(\mathrm{P}_{\mathrm{D}}\right)$ that a price spike will occur in the system, we computed $\mathrm{MC}_{\mathrm{n}}$ as the total market cost without a spike occurring and $\mathrm{MC}_{\mathrm{s}}$ as the total cost assuming a spike occurs. The total market cost considering the probability for half hour spike $\left(\mathrm{TMC}_{30}\right)$ is thus given as the following equation:

$$
\mathrm{TMC}_{30}=\mathrm{MC}_{\mathrm{S}}(\mathrm{t}) * \mathrm{P}_{\mathrm{D}}+\mathrm{MC}_{\mathrm{n}}(\mathrm{t}) *\left(1-\mathrm{P}_{\mathrm{D}}\right)
$$

Subject to constraints:

$$
\begin{aligned}
& M C_{S}(t)=\int_{t=1}^{t=n}\left[\left(S_{s}(t) \cdot P(t) \cdot D(t) \cdot U(t)\right) d t\right]+K \\
& M C_{n}(t)=\int_{t=1}^{t=n}\left[\left(S_{n}(t) \cdot P(t) \cdot D(t) \cdot U(t)\right) d t\right]+K
\end{aligned}
$$

\subsubsection{Half Hour Spike Case}

Equations (1) to (5) and (7) to (10) were used to compute the numerical results of optimisation of the air conditioning considering the probability that a half hour spikes may occur in the middle of the day, as shown in Figures 6 and Table III. Figures 5 and 6 indicate the numerical results of air conditioning optimisation if a spike may occurs (with 2.2\% probability) and no spike may occurs (with 97.8\% probability) in the middle of the day. The inside room temperatures were under the maximum permitted temperature and above the minimum permitted temperature. Figures 5 and 6 illustrate that the time and inside room 
temperature for switch numbers 1 to 4 were equal. This is because, during this time, the probability of a spike was not considered. In contrast, due to the probability of the spike in the middle of the day, the characteristics of switch numbers 5 to 20 were not identical. Figure 6 demonstrates the application of a pre-cooling method before a spike happens in the middle of the day. The room temperature dropped to less than $20^{\circ} \mathrm{C}$. This temperature is called a pre-cooling temperature. The air conditioning status when the spike started to happen was off until the duration of the spike was nearly expired. As a result, the room temperature when the spike happened only dropped to $21.5^{\circ} \mathrm{C}$. In contrast, as the spike probability was not considered for the no-spike case, the room temperature dropped to $21^{\circ} \mathrm{C}$, as shown in Figure 6.

It is clear from Figures 5 that a pre-cooling method was necessary to minimise the energy cost if considering the spike probability. The control system applied a pre-cooling method to avoid expensive cost when the spike happens. This was because there is a substantial risk of the price spike. The total cost could then be numerically optimised by varying the 36 switch edges. There were 20 switches of spike cases and 20 switches of no-spike, with a remaining 16 switches for both of them under different scenarios. Similar to the process described above, the cost could be calculated according to the air conditioning status. The cost of a price spike case was more expensive than the cost of a no-spike case. The total market cost $\left(\mathrm{TMC}_{30}\right)$, market cost spike $\left(\mathrm{MC}_{30}\right)$ and market cost no spike $\left(\mathrm{MC}_{\mathrm{n}}\right)$ are given in Table 3.
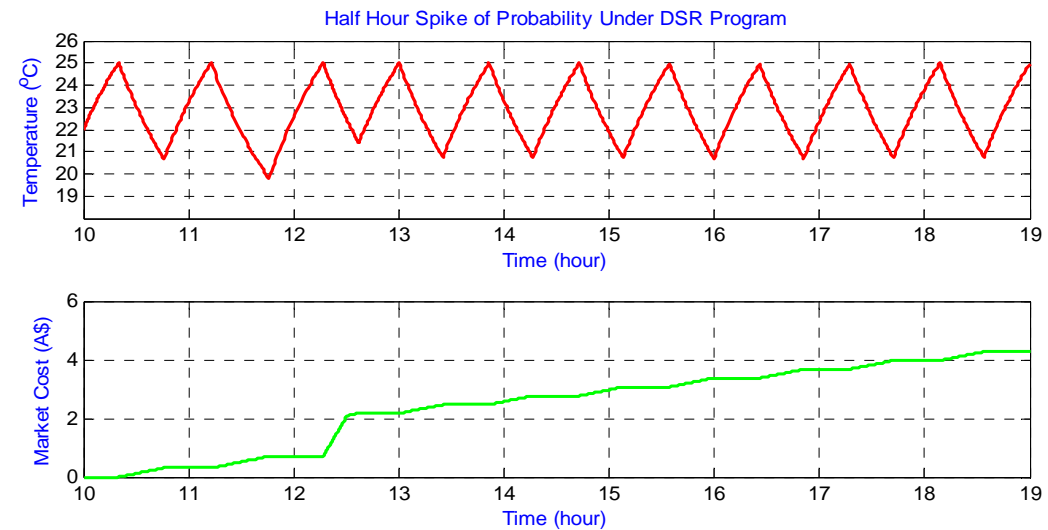

Figure 5. Numerical result of half hour spike probabilty case
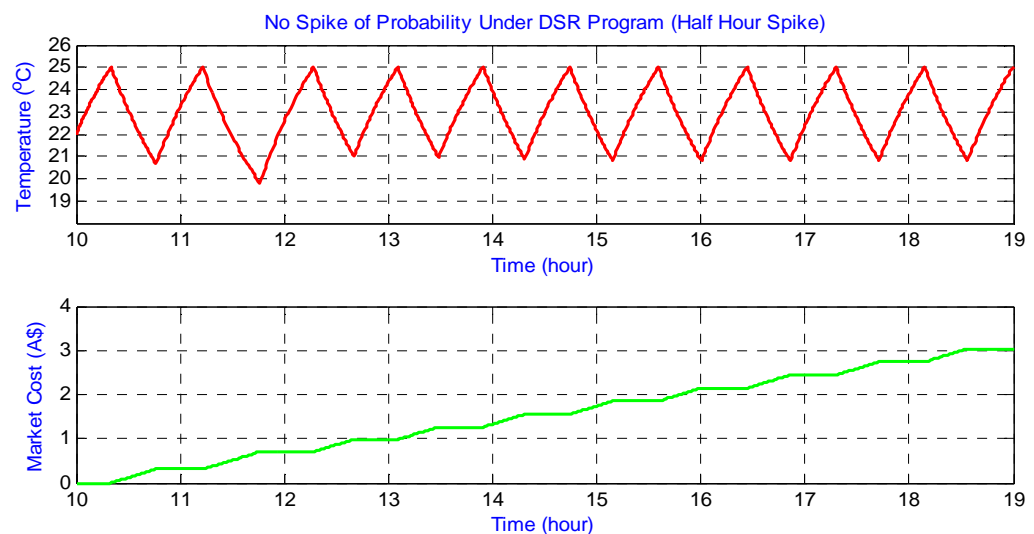

Figure 6. Numerical result of no-spike probability case (half hour spike)

Table 3. Total Market Cost for Half Hour Spike Case Considering to the Probability Spike

\begin{tabular}{ccc}
$\mathrm{TMC}_{30}(\mathrm{~A} \$)$ & $\mathrm{MC}_{30}(\mathrm{~A} \$)$ & $\mathrm{MC}_{\mathrm{n}}(\mathrm{A} \$)$ \\
\hline 3.06 & 4.27 & 3.03 \\
\hline
\end{tabular}




\subsection{Benefit of DSR}

Based on the results of the optimisation reported above, the consumer and aggregator could gain collective benefits when the consumer controls the air conditioning under the DSR program. The collective benefit (CB) is expressed by the following equation:

$$
\mathrm{CB}_{30}=\mathrm{MC}_{1}-\mathrm{TMC}_{30}
$$

The percentage of collective benefit is illustrated by the following equations:

$$
\%\left(\mathrm{CB}_{30}\right)=\frac{\mathrm{CB}_{30}(\mathrm{~A} \$)}{\mathrm{MC}_{1}(\mathrm{~A} \$)}
$$

Equations (11) to (12) were used to compute the collective benefit. Table 4 summarises the collective benefit for the consumer and aggregator when the consumer applied the DSR program if a spike may only occur in the middle of the day considering to the probability spike.

Table 4. Collective Benefit if Spike May Only Occur in the Middle of Day

\begin{tabular}{lcccc}
\hline \multirow{2}{*}{ Spike Duration } & $\begin{array}{c}\text { Without DSR } \\
\mathrm{MC}_{1} \quad(\mathrm{~A} \$)\end{array}$ & $\begin{array}{c}\text { Under DSR TMC } \\
(\mathrm{A} \$)\end{array}$ & $\begin{array}{c}\text { Collective Benefit } \\
\text { (A\$) }\end{array}$ & $\begin{array}{c}\text { (\%) } \\
\end{array}$ \\
\hline Half Hour Spike & 5.99 & 3.06 & 2.93 & $48.91 \%$ \\
\hline
\end{tabular}

As presented in Table 4, the consumer and aggregator can earn collective benefits if the DSR program is applied to meet a price spike considering the spike probability; for example, 2.93 A\$ (48.91 \%) for a half hour spike. This result indicates the pre-cooling method was effective to minimise the energy cost when a spike happens. Even though the spike probability was smaller, the pre-cooling method was required to anticipate high costs when a spike happens. The pre-cooling method was only applied when there was a substantial risk of a price spike.

\section{CONCLUSION}

This paper has demonstrated that the proposed DSR model allows consumers to manage and control air conditioning for every period based on the electricity market price. The model is applicable for both residential and commercial consumers to minimise the cost of fluctuating energy prices. The proposed model can assist the consumer to optimise the energy cost of air conditioning to meet a price spike. This result indicates that, the consumer should apply the pre-cooling method to minimise energy costs by anticipating the electricity price spike when we know the spike may occur in the middle of the day. In addition, a precooling method should be applied to avoid high electricity prices at critical times. However, pre-cooling should only be undertaken when there is a substantial risk of a price spike.

\section{REFERENCES}

[1] Singh., S.K. and P.S.S. More, " Demand Side Management Potential at the Bharati Hospital and Research Centre, "International Journal of Electrical and Computer Engineering (IJECE). 2: pp. 511518, 2012

[2] Ali Mansouri, et al., " Evaluation of Power System Reliability Considering Direct Load Control Effects, "International Journal of Electrical and Computer Engineering (IJECE). Vol. 3,: pp. 254-259, 2013

[3] Duy Thanh Nguyen, "Demand Response eXchange in a Deregulated Environment," in School of Engineering University of Tasmania: Tasmania, 2012

[4] Marwan, G. Ledwich, and A. Ghosh, " Demand-side response model to avoid spike of electricity price, "Journal of Process Control. 24: pp. 782-789, 2014

[5] Marwan, "Smart Grid-Demand side response model to mitigate price and peak impact on the electrical system," in Scince and engineering facultyQueensland University of Technology: Brisbane, 2013

[6] Su, C.-L., "Optimal demand-side participation in day-ahead electricity markets," in Faculty of Engineering and Physical SciencesManchester: Manchestr,U.K, 2007

[7] Australian Energy Market Operator, "Current Trading Interval Price and Demand Graph Queensland," "Australian Energy Market Operator, Editor, 2012 
[8] Christian Crowley, "Weather Effects on Electricity Loads: Modeling and Forecasting," Department of Economics The George Washington University: Washington, 2005

[9] Queensland Government, "Building Climate Smart in Queensland," "Department of Environment and Resource Management, Editor Queensland Government: Brisbane, 2008

[10] Peterson, M., "Managing Peak Demand," in EE-OZ Annual Conference: Gold Coast Brisbane, 2010

[11] Borlick, R., " Paying for Demand-Side Response at the Wholesale Level: The Small Consumers' Perspective, "The Electricity Journal. 24: pp. 8-19. 2011

[12] Jia, W., C. Kang, and Q. Chen, " Analysis on demand-side interactive response capability for power system dispatch in a smart grid framework, "Electric Power Systems Research. 90: pp. 11-17. 2012

[13] Xu, Y. and K. Nagasaka, " A Research on Spike Jump of Electricity Price in the Deregulated Power Markets, "International Journal of Electrical and Power Engineering. 3: pp. 99-104. 2009

[14] Ai, X., et al. "Bid-scheduling of demand side reserve based on demand response considering carbon emission trading in smart grid." in Critical Infrastructure (CRIS), 2010 5th International Conference on. 2010.

[15] Perfurmo, C., J.K. Ward, and Julio H. Braslavsky. "Reducing Energy Use and Operational Cost of Air Conditioning Systems With Multy Objective Evolutionary Algorithms,." in Conference Evolutionary Computation (CEC). 2010.

[16] Lee, S.C., S.J. Kim, and a.S.H. Kim, " Demand Side Management With Air Conditioner Loads Based on the Queuing System Model, " IEEE Transactions on Power Systems,. 26: pp. 661-668. 2011

[17] Hadban, Y.A., "Demand-Side Management in Office Buildings in Kuwait through an Ice-Storage Assisted HVAC System with Model Predictive Control,," in School of EngineeringCranfiled University: Kuwait, 2005.

\section{BIOGRAPHIES OF AUTHORS}

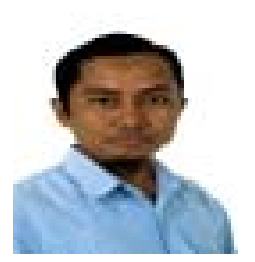

Dr. Marwan Marwan received the B.Eng degree from Hasanuddin University Makassar Indonesia, the M.Eng degree and the Ph.D from Queensland University of Technology (QUT) Brisbane Australia, in 2000, 2006 and 2013 respectively, all in electrical power engineering. He has been a lecturer with the State Polytechnic of Ujung Pandang Makassar Indonesia since 2001 until currently, in Electrical Engineering Department.

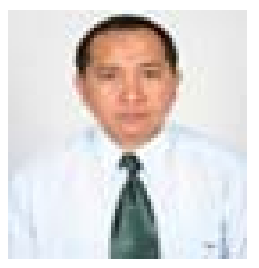

Dr. Pirman, M.Si recived the B.Eng degree from Hasanuddin University Makassar Indonesia, the master dan doctor degrees from Bandung Institute Technology in 1987, 1994 and 2001 respectively, all in Chemical Engineering. He has been a lecturer at Polytechnic State of Ujung Pandang since 1989 until currently in Chemical Engineering Department 